\title{
Bio-Based Rigid Polyurethane Foam from Liquefied Products of Wood in the Presence of Polyhydric Alcohols
}

\author{
Zhifeng Zheng, a , Hui Pan ${ }^{2, b}$, Yuanbo Huang ${ }^{1, c}$ and Y. Hse Chung ${ }^{3, d}$ \\ ${ }^{1}$ Key Laboratory of Forest Resources Conservation and Use in the Southwest Mountains of China \\ (SWFU), Ministry of Education, Southwest Forestry University, Kunming 650224, China \\ ${ }^{2}$ Calhoun Research Station, Louisiana State University AgCenter, Calhoun, Louisiana 71225, USA \\ ${ }^{3}$ Southern Research Station, USDA Forest Service, Pineville, Louisiana 71360, USA \\ azhengzhifeng@swfu.edu.cn, ${ }^{\mathrm{b}} \mathrm{hpan} @$ agcenter.Isu.edu, ${ }^{\mathrm{c} y o u t h s h o w @ 163 . c o m, ~}{ }^{\mathrm{d}}$ chse@fs.fed.us
}

Keywords: Polyurethane Rigid Foam; Liquefaction; Southern Pine; Microwave Heating

\begin{abstract}
Rigid polyurethane foams were prepared from the liquefied wood polyols, which was obtained by the liquefaction of southern pine wood in the presence of polyhydric alcohols with sulfuric acid catalyst by using microwave-assistant as an energy source. The properties of liquefied biomass-based polyols and the rigid polyurethane foams were investigated. The results indicated that the foams exhibited excellent mechanical properties.
\end{abstract}

\section{Introduction}

Polyurethane foams (PU Foams) are used widely in many fields as heat-insulating, packaging, structural, flotation and load bearing materials, due to their ease of processing and unique combination of excellent thermal insulation and mechanical properties. However, the raw materials for preparing traditional PU foams, based on polyol (polyether of polyester polyols) and isocyanate, are obtained mainly from fossil resources. With increasing concern of the shortages of fossil resources and the impetus for reducing costs of polyurethane, preparation of polyols from renewable biomass resources has been an interesting subject in the polyurethane industry. Biomass as natural polymer contains more than one hydroxyl group in the molecular chains, and can be used as polyol for preparing polyurethane materials. By the hydroxyalkylation reaction, polyols with desirable hydroxyl values and viscosities have been prepared from many hydroxyl-containing biomass substances [1-5]. These polyols have become important ingredients for rigid polyurethane foams because of the great functionalities of the starting materials.

There were also many reports concerning direct incorporation of biomass resources into polyurethane formulations [6-8]. However, except for a few cases, the biomass was insoluble in the polyols. In these cases, the biomass could only act as solid fillers rather than as reactive components in the foam structures, and as a result, foams with high densities were apt to be obtained.

Recently, liquefaction of biomass in the presence of some organic solvents has been developed [9]. It has been found that if polyhydric alcohols with appropriate molecular weights were used as reagents in the liquefaction of biomass, the resulting liquefied mixtures can be used directly as polyols to prepare polyurethane foams without any additional reaction of treatment [10-13].

In this study, many attempts have been made using the liquefaction technology with microwave-assistant to introduce wood into polyols for preparation of rigid PU foams. The properties of biomass-based polyols, the formulations and characteristics of rigid PU foams were investigated.

\section{Experimental}

Materials. Wood meal (southern pine, Pinus sp., 40 to 60 mesh) was dried in an oven at $105^{\circ} \mathrm{C}$ for 24 hours before use. Polyethylene glycol \#400 (PEG \#400, Mw=400), glycerin, sulfuric acid, and sodium hydroxide were of reagent grades and were obtained from commercial sources. Other ingredients 
included diphelylmethane diisocyanate (MDI) (MR100, by Huntsman ICI Chemicals LLC Ind. Ltd., U.S.A.), dibutyltin dilaurate (DBTDL) (Katsuta Ind. Ltd., Japan), and silicone surfactant SH193 (by Dow Corning Corporation, U.S.A.) were used as received.

Preparation of the liquefied biomass-based polyols. The liquefaction reagent was mixture of PEG \#400 and glycerin. Sulfuric acid was used as a catalyst. The liquefactions were carried out in a microwave extraction system. After the liquefaction, an equivalent amount of sodium hydroxide aqueous solution $(50 \%)$ was added to neutralize the sulfuric acid catalyst, thus the liquefied biomass-based polyols were obtained.

Measurements of properties of the liquefied biomass-based polyols. The specific gravity, apparent viscosities, acid amount and hydroxyl numbers of the liquefied biomass-based polyols were measured according to ASTM D 4669, ASTM D 4878, ASTM D 4662-08, and ASTM D 4274-05, respectively.

Preparation of the rigid foam. The $\mathrm{pH}$ of the liquefied biomass-based polyol obtained above was adjusted by adding $48 \mathrm{wt} \%$ sodium hydroxide aqueous solution. Thus, the definite amounts of biomass polyol, catalyst, surfactant, and water were premixed thoroughly in a plastics cup. Then, the prescript amount of MDI (at an isocyanate index of 80 to 120) was added and mixed quickly at a high stirring speed of 8,000 rpm for 10-15 seconds. The mixture then was poured immediately into a $17 \times 13 \times 13 \mathrm{~cm}$ cardboard box and was allowed to rise freely at room conditions. Foam was removed from the box after one hour and was allowed to cure at room temperature for two days before cutting into test samples.

Measurements of properties of the rigid foams. The apparent density of the rigid foam was measured according to ASTM D1622-08. Measurements of mechanical properties of the foams are based on the ASTM D1621-04a.

\section{Results and discussion}

Properties of the liquefied biomass-based polyols. Table 1 shows the properties of the liquefied biomass-based polyols obtained from microwave -assistant liquefaction by using sulfuric acid as the catalyst. There was not any residue in the liquefied mixture. So, the liquefied biomass-based polyols can be directly to use for preparing rigid PU foams.

Table 1. Properties of the liquefied biomass-based polyols ${ }^{\text {a) }}$

\begin{tabular}{ccccc}
\hline Reaction Time [min] & $\begin{array}{c}\text { Specific gravity } \\
{\left[\mathrm{g} / \mathrm{cm}^{3}\right]}\end{array}$ & $\begin{array}{c}\text { Apparent viscosity } \\
{[\mathrm{cP}]}\end{array}$ & $\begin{array}{c}\text { Hydroxyl value } \\
{[\mathrm{mg} \mathrm{KOH} / \mathrm{g}]}\end{array}$ & $\begin{array}{c}\text { Acid value } \\
{[\mathrm{mg} \mathrm{KOH} / \mathrm{g}]}\end{array}$ \\
\hline 5 & 1.13 & 1420 & 357 & 19.6 \\
30 & 1.13 & 1450 & 323 & 27.8 \\
60 & 1.13 & 1480 & 334 & 26.2 \\
120 & 1.13 & 1720 & 291 & 26.1 \\
\hline PEG \#400 & 1.12 & 140 & 280 & - \\
PEG \#400/glycerin $^{\text {b) }}$ & 1.16 & 360 & 700 & - \\
\hline
\end{tabular}

a) Microwave-assistant liquefaction condition: solvent composition: PEG \#400/glycerol/acid=70/30/3 (by weight), Wood/Solvent $=1 / 7(\mathrm{w} / \mathrm{w})$, Reaction Temperature of $150^{\circ} \mathrm{C} .{ }^{\mathrm{b})}$ PEG \#400/glycerin=70/30 (by weight).

As for the specific gravity of the liquefied mixture obtained by using sulfuric acid as the catalyst, it is higher than PEG \#400, but lower than the mixture of PEG \#400 and glycerin.

It has been reported that the viscosity of the mixture obtained by traditional heating is as high as $270,000 \mathrm{cP}$ [14]. Compared to the traditional heating liquefaction in our previous study, the viscosity of the liquefied mixture obtained by microwave-assistant liquefaction is lower by using the same acid as the catalyst, due to no wood solid residue remaining in the liquefied mixture. These values listed in Table 1 are somewhat larger than those of the fossil-based polyols, but are still suitable for the preparation of polyurethane foam. 
From the Table 1, the most significant change is the hydroxyl value (about half of the mixture of PEG \#400 and glycerin), especially in the initial period of the microwave-assistant liquefaction. Table 1 also shows that the hydroxyl value of the liquefied mixture decreases significantly and acidic substances are produced with increasing liquefaction time. This result suggests that apart from the alcoholysis reaction, dehydration and/or oxidation reactions also occur during the liquefaction.

Basic foam formulation for biomass-based polyols and their properties. The liquefied mixtures obtained above were used directly to prepare polyurethane foam by reaction with methylene diphenyl diisocyanate (MDI). Table 2 is the foam formulations for the liquefied biomass-based polyols. For improving the mixing efficiency and the foamability of the ingredients, to add a small amount of an appropriate PEG \#400 and use an organic tin catalyst, dibutyltin dilaurate (DBTDL), instead of triethylene diamine, are effective for the foaming. The characteristics of the foam obtained at different isocyanate index are shown in Table 3.

Table 2. Foam formulations for the liquefied biomass-based polyols

\begin{tabular}{clc}
\hline \multicolumn{1}{c}{ Ingredients } & Parts by weight \\
\hline A liquid: & Biomass-based polyol (12.5\% biomass con.) & 100 \\
& Catalyst (DBTDL) & 1 to 1.5 \\
& Surfactant (SH-193) & 2 to 2.5 \\
& Blowing agent (water, including the water from & \\
& Neutralization with NaOH solution) & 2 to 4.25 \\
& Additives (PEG \#400) & 15 \\
B liquid: & MDI & 100 to 240 \\
(isocyanate index) & 80 to 120 \\
\hline
\end{tabular}

Table 3. Mechanical properties of the foams

\begin{tabular}{|c|c|c|c|c|c|}
\hline $\begin{array}{c}\text { Reaction Time } \\
\text { [min] }\end{array}$ & $\begin{array}{l}\text { Isocyanate } \\
\text { Index }\end{array}$ & $\begin{array}{l}\text { Density } \\
{\left[\mathrm{g} / \mathrm{cm}^{3}\right]}\end{array}$ & $\begin{array}{c}\text { Compressive } \\
\text { Strength [Kpa] }\end{array}$ & $\begin{array}{c}\text { Apparent } \\
\text { Modulus [Mpa] }\end{array}$ & $\begin{array}{c}\text { Permanent } \\
\text { Deformation }^{\text {a) }}[\%]\end{array}$ \\
\hline \multirow[t]{3}{*}{${ }^{2}$} & 80 & 0.035 & 8.04 & 0.21 & 0.63 \\
\hline & 100 & 0.035 & 69.92 & 2.25 & 1.36 \\
\hline & 120 & 0.035 & 105.88 & 2.93 & 1.46 \\
\hline \multirow{3}{*}{30} & 80 & 0.034 & 6.68 & 0.16 & 0.83 \\
\hline & 100 & 0.037 & 61.00 & 1.35 & 1.46 \\
\hline & 120 & 0.035 & 90.08 & 2.47 & 2.91 \\
\hline \multirow{3}{*}{60} & 80 & 0.036 & 8.13 & 0.14 & 1.02 \\
\hline & 100 & 0.035 & 55.54 & 0.91 & 1.24 \\
\hline & 120 & 0.035 & 85.84 & 1.86 & 1.99 \\
\hline \multirow{3}{*}{120} & 80 & 0.036 & 8.76 & 0.22 & 1.13 \\
\hline & 100 & 0.037 & 49.54 & 1.35 & 1.59 \\
\hline & 120 & 0.035 & 69.65 & 1.66 & 1.79 \\
\hline \multirow{3}{*}{ PEG \#400 } & 80 & 0.035 & 7.65 & 0.16 & 1.92 \\
\hline & 100 & 0.035 & 52.44 & 1.21 & 2.14 \\
\hline & 120 & - & - & - & - \\
\hline mixture of PEG & 80 & 0.034 & 88.28 & 2.78 & 7.12 \\
\hline \#400 \& glycerin & 100 & 0.034 & 95.62 & 2.48 & 10.01 \\
\hline$(70 / 30, w / w)$ & 120 & 0.037 & 102.53 & 2.18 & 9.10 \\
\hline
\end{tabular}

a) The permanent deformations of the foams after compression tests (20\% strain)

From Table 3, compared to fossil-based polyols (especially mixture of PEG \#400 and glycerin), the foam made from liquefied biomass-based polyols has the lower compressive strength and elastic modulus. These results suggest that liquefied wood mixture can replace part of polyols for the preparation of polyurethane foam, but that will cause the compressive strength and modulus loss. However, the foams made from fossil-based polyols show more brittle than those made from liquefied biomass-based polyols. The permanent deformation of the foams after compression measurements (20\% strain) are more than $7 \%$ for the foams made from fossil-based polyols. Whereas, the permanent deformation of the foams made from biomass-based polyols are less $6 \%$. These results 
suggest that the introduction of wood evidently results in the foam with greater resilience. Some of the liquefied wood components can make contributions to the resilience of the resulting foams.

With the microwave-assistant liquefaction time increases, the foams made from the liquefied biomass-based polyols obtained show lower mechanical properties. That is attributed to the lower hydroxyl value at long liquefaction time. The compressive strength and apparent modulus increase at isocyanate index from 80 to 100 , then decrease at isocyanate index from 100 to 120 , except the liquefaction time $30 \mathrm{~min}$. These results are attributed to the lower density of the foam at isocyanate index 120, and the foam cells are bigger than those of the foam at isocyanate index 80 and 120. From Table 3, the foams made from the liquefied biomass-based polyols at $5 \mathrm{~min}$ of liquefaction time show the best mechanical properties at isocyanate index 120 .

\section{Conclusion}

Through the microwave-assistant liquefaction of wood, the liquefied biomass-based polyols can be obtained, which are uniform black liquid with no wood solid residue, $1.13 \mathrm{~g} / \mathrm{cm}^{3}$ of the specific gravity, the apparent viscosity in the range of 1420 to $1720 \mathrm{cP}$ and the hydroxyl value in range of 290 to $360 \mathrm{mg} \mathrm{KOH} / \mathrm{g}$. The biomass-based polyols are suitable for preparation of rigid polyurethane foams. The foams made from the polyols obtained at 5 min of liquefaction time show the best mechanical properties at isocyanate index 120 of the foam.

\section{Acknowledgements}

We are grateful for the financial supports of this research China National Natural Science Funds (No.30800867), Program for New Century Excellent Talents in University (No.NCET-10-0906), Key Projects of Chinese Ministry of Education (No. 209117), and Science \& technology funds of Yunnan province, China (No.2007C068M).

\section{References}

[1] J. E. Wilson and R. H. Fowler: Science, Vol. 128 (1958), p. 1343.

[2] M. Wismer, Gibsonia and J. F. Foote, U.S. Patent 3,085,085. (1963)

[3] F. Hostettler, R. K. Barnes and R. W. Mclaughlin, U.S. Patent 3,073,788. (1963)

[4] G. G. Allan, U.S. Patent 3,476,795. (1969)

[5] L. C.-F. Wu and W. G. Glasser: Journal Applied Polymer Science, Vol. 29 (1984), p. 111.

[6] F. Hostettler, U.S. Patent 4,156,759. (1979)

[7] H. Yoshida, R. Mörck, K. P. Kringstad and H. Hatakeyama: Journal of Applied Polymer Science, Vol. 34 (1987), p. 1187.

[8] R. L. Cunningham, M. E. Carr and E. B. Bagley: Journal of Applied Polymer Science, Vol. 44 (1992), p. 1477.

[9] N. Shiraishi, S. Onodera, M. Ohtani and T. Masumoto: Mokuzai Gakkaishi, Vol. 31 (1985), p. 418.

[10]Y. Yao, M. Yoshioka and N. Shiraishi: Mokuzai Gakkaishi, 39 (1993), p. 930.

[11]Y. Yao, M. Yoshioka and N. Shiraishi: Mokuzai Gakkaishi, 41 (1995), p. 659.

[12]S. H. Lee, M. Yoshioka and N. Shiraishi: Journal of Applied Polymer Science, 78 (2000), p. 319.

[13]J. Ge, Z. Zhang and J. Xu: Polymer Materials Science and Engineering, 19 (2003), p. 194. (In Chinese)

[14]Y. Kurimoto, S. Doi, Y. Tamura, Holzforschung, 1999, 53: 617-622. 
Advances in Building Materials

doi:10.4028/www.scientific.net/AMR.168-170

Bio-Based Rigid Polyurethane Foam from Liquefied Products of Wood in the Presence of Polyhydric Alcohols

doi:10.4028/www.scientific.net/AMR.168-170.1281 